\title{
Validation of tracheal intubation of wire-reinforced endotracheal tube with ultrasonography
}

\author{
GÖKHAN INANGIL, SÜLEYMAN DENIZ, SEDAT TEMIRCAN, ÖMER BAKAL, HÜSEYIN SEN, SEZAI ÖZKAN
}

Department of Anesthesiology, Gulhane Military Medical Academy, Haydarpasa Training Hospital, Istanbul, Turkey

Corresponding author:

Süleyman Deniz

Department of Anesthesia and Reanimation

Gulhane Military Medical Academy

Haydarpasa Training Hospital

Istanbul, Turkey

Phone: 00-90-535-6542540

Fax: 00-90-216- 3487880

E-mail:sdeniz.gata@gmail.com

IRB: 1491-57-14/1539

\section{ABSTRACT}

Objective. The use of ultrasonography (US) is a new method for verifying the location of the endotracheal tube.

Design. Our study was designed as a paired-data and investigator-blind clinical study for evaluating the effectiveness of US for verification of wire-reinforced endotracheal tube (WR-ETT) placement compared with capnography.

Setting. This study was conducted on 56 patients scheduled for elective surgery under general anesthesia.

Patients. Fifty patients completed the study as 6 were excluded for various reasons.

Intervention. Two different investigators performed the ultrasonography and intubation independently from one another. While investigator 1 attempted to verify the location of the WR-ETT with a portable ultrasonography with sagittal trans-tracheal view, investigator 2 intubated the patient and verified the location of the ETT using capnography.

Measurements. Time for verifying the location of the ETT using both US and capnography was recorded.

Main Results. When the ultrasonography method was compared with capnography for verification of the WR-ETT placement, the results showed $95.75 \%$ sensitivity and $100 \%$ specificity. The average verification times for endotracheal intubation were $12.78 \pm 7.46 \mathrm{~s}$. and $24.44 \pm 1.45$ s. with US and capnography, respectively ( $\mathrm{p}=0.003$ ). Conclusion. Our results suggest that ultrasound identification of a WR-ETT within the trachea is a rapid and accurate method for confirmation of tracheal placement. Larger studies are needed before widespread use of this technique.
Key words: endotracheal tube, intubation, ultrasonography, capnography

\section{INTRODUCTION}

Endotracheal intubation is the primary medical procedure used for securing the airway. Confirmation of endotracheal tube (ETT) placement is essential to prevent hypoxia and aspiration. (1-3) Methods used for verifying ETT location include: auscultation of chest and epigastrium, visualization of symmetrical thoracic movement and fogging inside the tube. But these methods are not sufficiently reliable. (1,4-6) Capnography, which detects end-tidal carbon dioxide, is considered as gold standard for verifying the placement of ETT. However, this method also has limitations. Capnography devices do not provide accurate results in cases with low cardiac output and airway obstruction or when epinephrine is used. (7-9) Accuracy of capnography in cardiac arrest is also unclear and studies suggest that up to six breaths may be required before the stomach is completely cleared of $\mathrm{CO} 2$, especially after prolonged bag valve-mask ventilation. The studies have demonstrated that quantitative waveform capnography is the most sensitive tool for confirming tracheal intubation. $(2,3,6,8,10)$ The use of ultrasonography (US) is a new method for verifying the location of the endotracheal tube (ETT) after intubation. $(4,7,11)$ Being non-invasive, cost-efficient and portable, ultrasonography devices are commonly used in emergency services, operating rooms and intensive care units. $(1,2,5)$

Many studies have recently been conducted on the verification of ETT location through US, including those that attempted to use trachea, diaphragm and intercostal approaches to verify ETT locations. (1-4,7,11-14) Several studies used special expressions, such as sign, bullet sign, comet-tail artifact, and double tract sign to verify the ETT location. $(4,7,12,14)$ Another interesting study focused on viewing the diaphragm at the subxiphoid level and observing the bilateral movement of the pleura with US in order to confirm proper placement of the ETT. (13) Since US allows for rapid visualization of structures that lay superficial to the oral, pharyngeal, or tracheal air columns which are not apparent until direct laryngoscopy, it can accurately delineate appropriate endotracheal tube size, placement, and assessment of airway edema prior to extubation. (15)

A wire-reinforced endotracheal tube (WRETT) is generally preferred to avoid kinking during head \& neck and neurosurgical cases. Reinforced tubes can also be useful in prone-positioned patients. $(16,17)$ Our study was designed as prospective, paired-data and investigator-blind clinical study for the purpose of evaluating the effectiveness of ultrasonography for verification of intubation with a wire-reinforced endotracheal tube compared to capnography.

\section{MATERIALS AND METHODS}

This study was designed as a prospective, paired and investigator-blinded study performed at the Department of Anesthesiology following the approval of the Institutional Review Board (Ref: 1491-5714/1539). All of the patients were informed about the details of the study and their 
written consents were obtained.

Patients eligible for study enrolment were American Society of Anesthesiologists (ASA) physical status I-II, aged 18-65, with body mass index (BMI) $<40 \mathrm{~kg} / \mathrm{m} 2$ who were admitted for elective surgery under general anesthesia and planned for WR-ETT (Sheridan Spiral-Flex ${ }^{\circ}$ Oral Reinforced Tubes, Hudson $\mathrm{RCI}^{\circ}$, Temecula, CA 92589-9020 USA) intubation such as intracranial, intra oral surgery (tonsillectomy, dental, gum and tongue surgery) and operations performed in prone position.

Exclusion criteria were: history of previous difficult intubation or suspected difficult intubation (Mallampati score of 3-4), emergency operations and intubations, abnormal airway anatomy including malignity, patients with low cardiac output and patients with high aspiration risk and esophageal disease. The patients who had severe bradycardia, hypotension and/or hypertension after induction of anesthesia, and patients with more than two unsuccessful intubation attempts were also excluded from the study.

Patient demographics, height, weight and BMI, ASA status and Mallampati scores were recorded.

The patients were hydrated with $8-10 \mathrm{ml} /$ $\mathrm{kg}$ of $0.9 \% \mathrm{NaCl}$ and midazolam $0.03 \mathrm{mg} /$ $\mathrm{kg}$ was administered for sedation. Standard monitoring (electrocardiography, noninvasive arterial blood pressure, heart rate, SpO2 measurement, temperature monitoring) was performed on all the patients.

Anesthesia was induced with $2 \mathrm{mg} / \mathrm{kg}$ of propofol and fentanyl $1 \mathrm{mcg} / \mathrm{kg}$, following mask ventilation, neuromuscular blockade was performed with vecuronium bromide $0.1 \mathrm{mg} / \mathrm{kg}$ and after two minutes of mask ventilation, endotracheal intubation was attempted by direct laryngoscopy.

Three investigators were involved in the procedure: one anesthesiologist performed the intubation and bag ventilation, the other performed the US and the third, independent anesthesiologist, administered anesthetic drugs and performed the auscultation. Investigators expressed their opinions simultaneously and independently from one other, and the information was recorded on a form. The investigator performing US was blinded from communicating verbally with the others by wearing headphones and a drape was attached to prevent visual contact.

Investigator 1: An experienced investigator, had received US training prior to the procedure and observed intubation with sagittal transtracheal US 20 times before the study. He performed US using transportable ultrasound equipment (SonoSite

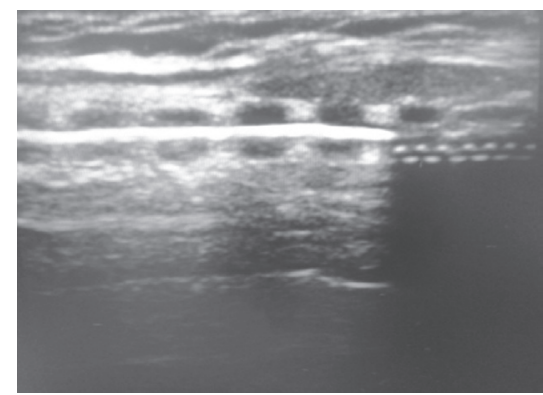

Figure 1. The image of the wire-reinforced endotracheal tube (White arrow), orange arrows: tracheal rings

M-Turbo; SonoSite Inc, Bothell, WA) with an HFL $38 \mathrm{~mm} \mathrm{13-6} \mathrm{MHz}$ linear array transducer. The probe was placed sagittally between cricothyroid membrane and suprasternal notch during anesthesia induction. The investigator recorded time for verification of endotracheal intubation with US. Verification time was accepted as the time between the WR-ETT passing the vocal cords and recognition of the image (figure 1). The US probe was moved to the right and left or in tilted position in order to view better imaging. If the investigator was unable to view the WR-ETT on the trachea within 30 seconds, he recorded the result as 'image not acquired' and he did not check the tube location further, regardless whether the tube was on the esophagus or not.

Investigator 2: Anesthesiologist, with at least 3 years of experience, used a Macintosh blade number 3-4 to perform the endotracheal intubation after induction of anesthesia and neuromuscular blockade. Maximum number of attempts was limited to two. Laryngoscopic view was classified using the Cormack-Lehane (C-L) classification and recorded. After the tube had passed through the vocal cords, manual bag-valve-mask ventilation was initiated. Capnography waveforms showing a quantity of $>4 \mathrm{mmHg} \mathrm{CO} 2$ after six ventilations were used as the criteria for confirming endotracheal intubation. (7) The investigator recorded the time for verifying the location of the ETT using capnography.

Investigator 3: As a standard protocol, the third anesthesiologist auscultated the epigastrium first, then right and left hemithorax, respectively.

\section{STATISTICS}

In a small pilot study conducted on $10 \mathrm{pa}-$ tients, the standard deviation (SD) for verification time of WR-ETT by US was approximately $12 \mathrm{~s}$. It was estimated that the SD difference between the two methods

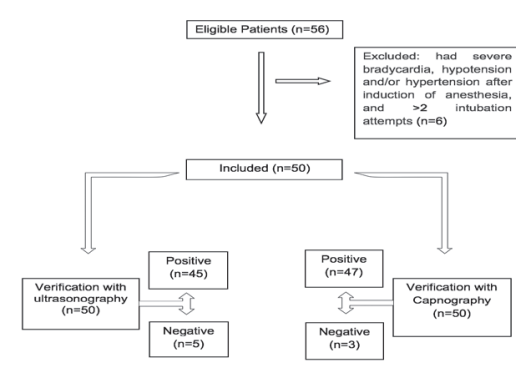

Figure 2. Study flow diagram

would be approximately 9 s. An SD ratio of 0.9 , with a two-tailed $\alpha$ error of $5 \%$ and a $\beta$ error of $20 \%$, results and a final power of $80 \%$ could be reached by enrolling 40 patients in the study. The possibility of exclusion during the study was taken into consideration and therefore, the number of the patients was raised by $40 \%$ and their number determined as 56 .

Statistical analysis was done with the SPSS for Windows 15.0 (Chi, IL, USA) statistical package program. Descriptive statistics were given as frequency, mean, standard deviation and proportions. A 2-by-2 table was used to calculate the sensitivity and specificity, for determination of tube placement. For comparison of methods, a paired t-test was used and P-value less than 0.05 were considered statistically significant.

\section{RESULTS}

56 patients in total were enrolled but 6 patients (4 had severe bradycardia, hypotension and/or hypertension after induction of anesthesia, 2 had more than two intubation attempts) were excluded from the study. Thus, 50 patients were available for comparison of methods. Baseline characteristics of the patients are shown in table 1. After endotracheal intubation, ETT was verified in trachea with US in 45 patients, while capnography verified 47 endotracheal intubation and 3 patients were not verified with capnography but with esophageal intubation (figure 2). When US method was compared to capnography for verifying endotracheal placement of ETT, there was $95.75 \%$ sensitivity and $100 \%$ specificity.

Upon comparing ultrasound with capnography, there was a significant difference between the two methods. The average time for verification between US and capnography was $12.78 \pm 7.46 \mathrm{~s}$. and $24.44 \pm 1.45 \mathrm{~s}$., respectively $(\mathrm{p}=0.003)$. 
Table 1. Baseline Characteristics of the Patients. Mean $\pm S D$

\begin{tabular}{ll}
\hline Age $($ years $)$ & $42.9 \pm 16.4$ \\
\hline Height $(\mathrm{cm})$ & $170 \pm 8.8$ \\
\hline Weight $(\mathrm{kg})$ & $73.9 \pm 13.4$ \\
\hline Body Mass Index (kg/m2) & $25.6 \pm 4.4$ \\
\hline Gender (Female/Male) & $22 / 28$ \\
\hline ASA Score (I / II) & $33 / 17$ \\
\hline Mallampati Score (I / II) & $34 / 16$ \\
\hline C-L Classification ((I-II) / (III-IV)) & $41 / 9$
\end{tabular}

ASA, American Society of Anesthesiologists; C-L, Cormack-Lehane.

\section{DISCUSSION}

In this, prospective, paired-data and investigator-blind clinical study, we found that the use of the US for verification of the location of WR-ETT had a high success rate, providing approximately 2 times faster results than capnography.

US was initially used on newborn babies to verify intubation in a 1986 study conducted by Slovis et al. (11) The aortic arch was taken as the reference point, and $85 \%$ of the intubations provided accurate results.

The studies reported that sensitivity and specificity rates of the quantitative waveform capnography during verification of the ETT location were $100 \%$ and $100 \%$, respectively. $(2-4,6,10)$ Therefore, we viewed quantitative waveform capnography as the gold standard method for use in verifying WR-ETT location and compared it with US in our study. The capnography device may not give accurate results in cases such as low cardiac output, low pulmonary flow, and airway obstruction or when epinephrine is used. (7-9) Therefore we excluded cases with low cardiac output from the study.

The studies in which US was used to verify standard ETT location have sensitivity and specificity rates of $62.5 \%$ and $75 \%$, respectively. (1,2,11-14) We determined the sensitivity and specificity rates as $95.75 \%$ and $100 \%$. This result demonstrates that the verification of WR-ETT through US had a high success rate. Since no prior study has been conducted on the verification of WRETT through ultrasonography, the data we obtained can be used as a reference for other studies.

In a study Stuntz R et al. (1) conducted on a cadaver, the average amount of time it took to verify ETT location through US was $24.7 \mathrm{~s}$. In another study, conducted by Adi $\mathrm{O}$ et al. (2) the average time was re- ported to be $16.4 \mathrm{~s}$, , and ultrasonography was found to be faster than capnography for verifying ETT location. Chou HC et al. $(7,14)$ calculated the time for verifying ETT location as $14 \mathrm{~s}$ similarly to our study as it took $12.7 \mathrm{~s}$ to verify WR-ETT location through US. This time was equal to half of the average verification time through capnography. This can be attributed to the rapid recognition of the WR-ETT image on US.

Laryngoscopic imaging and intubation success are different concepts. Nearly all of the studies in the literature, including our study, took the laryngoscopic image classification as the basis for intubation success. (18-20) The classification defined by Cormack-Lehane is the most popular laryngoscopic imaging method used in complex airway estimation. $(19,20)$ The C-L III-IV laryngoscopic image is used in practice as an indicator of a complex intubation. (18-20) It should, however, be noted that the improvement of laryngoscopic imaging conditions does not necessarily mean higher intubation success. (20) Although larynx and glottis are imaged very clearly, placing and advancing the endotracheal tube through trachea can sometimes fail. (20) In our study, the number of C-L III-IV patients was determined as $9(18 \%)$.

Imaging the upper airway in obese patients through ultrasonography is a complicated procedure. (21) In our study, where the image of the WR-ETT on US was studied for the first time, we excluded the patients whose BMI was $\geq 40$, as we wanted to prevent any unnecessary loss of time. This exclusion, however, served as one of the limitations to our study. Therefore, we plan to conduct a similar study on obese patients as soon as possible.

Another limitation to this study was the absence of esophagus imaging through US. Again, we chose not to use esophageal im- aging as this would lead to the loss of time for our study since we focused on sagittal transtracheal US for endotracheal confirmation of WR-ETT.

The high sensitivity and specificity rates observed in our study may have partially resulted in excluding the patients suspected of having complex airways (Mallampati III-IV, the patients who have an anatomical deformity of airways) and high risk patients (patients who required urgent surgery or who had low cardiac output) from the study.

Although we emphasize in our study that the sensitivity and specificity of capnography for verifying ETT location was $100 \%$, a meta-analysis conducted by Li et al. (8) determined that the sensitivity and specificity of capnography in 2,192 intubations were $93 \%$ and $97 \%$, respectively. As seen from these results, no single method seems to be sufficient for verification of endotracheal intubation. (3) There are also some reports stating that confirmation of optimal ETT depth is possible with US when saline is used to inflate cuff in contrast to capnography, since it does not distinguish between endobronchial and endotracheal intubation. Auscultation may also be insufficient since background noise interferes in emergency department especially. $(22,23)$ Thus, US is a promising approach for confirming not only endotracheal intubation, but also the proper placement of the ETT.

Consequently, the WR-ETT has a very distinctive appearance with sagittal transtracheal US, resulting in high sensitivity and specificity rates for endotracheal intubation verification. Our results suggest that ultrasound identification of a WR-ETT within the trachea is a rapid and accurate method for confirming the tracheal placement. Larger studies are needed before this technique becomes widely used. 


\section{REFERENCES}

1. Stuntz R, Kochert E, Kehrl T, Schrading W. The effect of sonologist experience on the ability to determine endotracheal tube location using transtracheal ultrasound. Am J Emerg Med 2014;32:267-9.

2. Adi O, Chuan TW, Rishya M. A feasibility study on bedside upper airway ultrasonography compared to waveform capnography for verifying endotracheal tube location after intubation. Crit Ultrasound J 2013;5:7.

3. Pfeiffer P, Rudolph SS, Børglum J, Isbye DL. Temporal comparison of ultrasound vs. auscultation and capnography in verification of endotracheal tube placement. Acta Anaesthesiol Scand 2011;55:1190-5.

4. Abbasi S, Farsi D, Zare MA, Hajimohammadi M, Rezai M, Hafezimoghadam P. Direct ultrasound methods: a confirmatory technique for proper endotracheal intubation in the emergency department. Eur J Emerg Med 2015;22:10-6.

5. Werner SL, Smith CE, Goldstein JR, Jones RA, Cydulka RK. Pilot study to evaluate the accuracy of ultrasonography in confirming endotracheal tube placement. Ann Emerg Med 2007;49:75-80.

6. Muslu B, Sert H, Kaya A, Demircioglu RI, Gözdemir M, Usta B, et al. Use of sonography for rapid identification of esophageal and tracheal intubations in adult patients. J Ultrasound Med 2011;30:671-6.

7. Chou HC, Chong KM, Sim SS, Ma MH, Liu SH, Chen NC, et al. Real-time tracheal ultrasonography for confirmation of endotracheal tube placement during cardiopulmonary resuscitation. Resuscitation 2013;84:1708-12

8. Li J. Capnography alone is imperfect for endotracheal tube placement confirmation during emergency intubation. J Emerg Med 2001;20:223-9.

9. Levine RL, Wayne MA, Miller CC. End-tidal carbon dioxide and outcome of out-of-hospital cardiac arrest. N Engl J Med 1997;337:301-6.

10. Vaghadia H, Jenkins LC, Ford RW. Comparison of end-tidal carbon dioxide, oxygen saturation and clinical signs for the detection of oesophageal intubation. Can J Anaesth 1989;36:560-4.

11. Slovis TL, Poland RL. Endotracheal tubes in neonates: sonographic positioning. Radiology 1986;160:262-3.

12. Park SC, Ryu JH, Yeom SR, Jeong JW, Cho SJ. Confirmation of endotracheal intubation by combined ultrasonographic methods in the Emergency Department. Emerg Med Australas 2009;21:293-7.

13. Kristensen MS. Ultrasonography in the management of the airway. Acta Anaesthesiol Scand 2011;55:1155-73.

14. Chou HC, Tseng WP, Wang CH, Ma MH, Wang HP, Huang PC, et al. Tracheal rapid ultrasound exam (T.R.U.E.) for confirming endotracheal tube placement during emergency intubation. Resuscitation 2011;82:1279-84.

15. Fulkerson JS, Moore HM, Anderson TS, Lowe RF Jr. Ultrasonography in the preoperative difficult airway assessment. J Clin Monit Comput(2016) doi:10.1007/s10877-016-9888-7

16. Kumar R, Gupta E, Kumar S, Rani Sharma K, Rani Gupta N. Cuff inflation-supplemented laryngoscope-guided nasal intubation: a comparison of three endotracheal tubes. Anesth Analg 2013;116:619-24.

17. Dimitriou VK, Zogogiannis ID, Douma AK, Pentilas ND, Liotiri DG, Wachtel MS, et al. Comparison of standard polyvinyl chloride tracheal tubes and straight reinforced tracheal tubes for tracheal intubation through different sizes of the Airtraq laryngoscope in anesthetized and paralyzed patients: a randomized prospective study. Anesthesiology 2009;111:1265-70.

18. Singh M, Chin KJ, Chan VW, Wong DT, Prasad GA, Yu E. Use of sonography for airway assessment: an observational study. J Ultrasound Med 2010;29:79-85.

19. Apfelbaum JL, Hagberg CA, Caplan RA, Blitt CD, Connis RT, Nickinovich DG, Hagberg CA, Caplan RA, Benumof JL, Berry FA, Blitt CD, Bode RH, Cheney FW, Connis RT, Guidry OF, Nickinovich DG, Ovassapian A; American Society of Anesthesiologists Task Force on Management of the Difficult Airway. Practice guidelines for management of the difficult airway: an updated report by the American Society of Anesthesiologists Task Force on Management of the Difficult Airway. Anesthesiology 2013;118:251-70.

20. Burkle CM, Walsh MT, Harrison BA, Curry TB, Rose SH. Airway management after failure to intubate by direct laryngoscopy: outcomes in a large teaching hospital. Can J Anaesth 2005;52:634-40.

21. Aslani A, Ng SC, Hurley M, McCarthy KF, McNicholas M, McCaul CL. Accuracy of identification of the cricothyroid membrane in female subjects using palpation: an observational study. Anesth Analg 2012;114:987-92.

22. Tessaro MO, Arroyo AC, Haines LE, Dickman E. Inflating the endotracheal tube cuff with saline to confirm correct depth using bedside ultrasonography. CJEM 2015;17:94-8.

23. Tessaro MO, Salant EP, Arroyo AC, Haines LE, Dickman E. Tracheal rapid ultrasound saline test (T.R.U.S.T.) for confirming correct endotracheal tube depth in children. Resuscitation 2015;89:8-12. 